\title{
Experimental study comparing burn healing effects of raw South African Shea butter and the samples from a Libyan market
}

\author{
Soad A. Treesh ${ }^{1 *}$, Sakina S. Saadawi ${ }^{2}$, Khairi A. Alennabi ${ }^{3}$, Suhera M. Aburawi ${ }^{4}$, Kholoud Lotfi ${ }^{2}$ and Amal S. Ben Musa \\ ${ }^{1}$ Department of Histology and Medical Genetics, Faculty of Medicine, University of Tripoli, Tripoli, Libya \\ ${ }^{2}$ Department of Pharmacognosy, Faculty of Pharmacy, University of Tripoli, Tripoli, Libya \\ ${ }^{3}$ Department of Environment, Food and Biological Applications, Biotechnology Research Centre, Tripoli, Libya \\ ${ }^{4}$ Department of Pharmacology and Clinical Pharmacy, Faculty of Pharmacy, University of Tripoli, Tripoli, Libya
}

\begin{abstract}
Background: The fat extracted from the nut of the African Shea tree (Vitellaria paradoxa) is called Shea butter. It has multiple uses at the local level as it is used in cosmetic products and as a cocoa butter substitute in chocolate industries. It has a high nutritious value and is also a valuable product on the local, national, and international markets, making it the ideal candidate to research and invest in.

Aim: This study is a comparative experimental study of the possible burn healing effects between imported South African raw Shea butter and samples in a Libyan market.

Method: The control samples were brought from South Africa (Benin traditional markets). A total of 18 different samples were collected from different sale centers in Tripoli, including pharmacies, beauty shops, and spices shops, in addition to one sample brought from Poland. Animal experiment on burn healing effect was carried out on nine male Sprague Dawley (350-400 g) rats aged 6-8 weeks old. After shaving the animal's dorsum hair, a metal cube was used to create a deep second degree burn wound, and the cube was heated to $100^{\circ} \mathrm{C}$ for 20 seconds. Medication with Shea butter (control, T1, and T2) was initiated daily for one for these groups by the application of a thin film of the Shea butter samples on the burned areas. On days 1, 3, and 7, the rats were anesthetised and a sample from the burned scar tissue and skin adjacent were evaluated using pathological parameters.

Results: The histological study indicates that the use of Shea butter T1 as topical treatment induces an immune response, which enhances the form of the presence of a large number of inflammatory cells in the epidermis and dermis layers. The treatment of burned skin with T2 lasted for 72 hours and it showed slightly significant healing in the normal structure of proliferative granulation tissue with accumulation of fibroblasts and inflammatory cells surrounding the sebaceous glands and hair follicles. Small areas of the epidermis which formed few layers were observed and some hair roots were grown. This was well seen in cases of T1 and T2. Shea butter bought as raw might have a bad effect on burned skin.

Conclusion: Shea butter bought as raw might have bad effect on burned skin. On the other hand, the sample from Poland had a therapeutic effect, which was because of the additives such as avocado oil, grape seed oil, and others.

Keywords: Burnt skin, Histopathology, Shea butter.
\end{abstract}

\section{Introduction}

In traditional medicine, Shea butter has been employed in the treatment of several ailments. It supports wound healing and decreases skin irritation. Shea butter is also used as an anti-inflammatory agent, treats rashes in children, dermatitis, chapping, and ulcers (Hong et al., 1996). Cosmetics, especially moisturizers, and lipsticks use Shea butter. As a result, cosmetic industries' markets use this ingredient in soaps, shampoo, and skin cream preparations (Hall et al., 1996).

A burn can be defined as a skin damage that is caused by excessive heat or chemicals. The most common burn injuries are caused by heat exposure and chemicals. Full-thickness burns usually develop, causing immediate cell death and matrix destruction. The most severe damage occurs in the wound surface (Williams, 2001). Depending on the treatment approach, tissue injury beneath the nonviable surface can be induced by additional heat and inflammation that can be healed over time or can develop necrosis. Managing a burn wound can be challenging due to the necessity of continuous adaptation of treatment to the change in wound biology, dictated by the burn injury process, response to injury, and environment of wound (Demling and Seigne, 2000). The common complications of burn injury are caused by the loss of the normal skin barrier function. These include infection, body heat loss, increased evaporative water loss, and change in touch and appearance.

Burn severity can be determined depending on burn depth, size, location, and age of patient. Burn size can be described by the percentage of the total body surface area that is exposed to the burn. Age is considered a major determining factor in a patient's prognosis. Infants and the elderly have a higher risk and mortality 
rate compared to older children and young and middleaged adults (Monafo and Bessy, 2001).

The degree of heat exposure and depth of heat penetration are the determining factors to the depth of heat injury. Wet heat (scald) can move faster and more easily into tissues compared to dry heat (flame); this is because water transfers heat 100 times faster than air. Moreover, skin thickness is critical; the thinner the skin, the broader the burn will be due to less residual dermis (DeSanti, 2005). Babies, children, and elderly people have thin skin and so they are at risk for deeper burns compared to younger adults to the same heat exposure (DeSanti, 2005).

Burn depth is defined by how much of the skin's layers are destroyed by the source of heat and it is the determining factor that affects wound management. Formerly, burn wounds were categorized depending on the degrees: first, second, third, and fourth degree. However, it is more definite to assign burn wound depth by the anatomic thickness of the skin implicated as follows: a superficial burn is restricted to the outer epidermal layer; a partialthickness burn includes the epidermal layer and part of the inner dermis; a full-thickness burn includes the destruction of both epidermis and dermis; and a subdermal burn includes destruction of both layers and extending to the lower tissues, including fat, tendons, muscle, and bone (DeSanti, 2005).This study is a comparative experimental study of the possible burn healing effects between imported raw South African Shea butter samples and samples from a Libyan market on burnt skin.

\section{Materials and Methods \\ Animal's preparation \\ Ten male Sprague Dawley rats (350-400 g, 6-8 weeks old)} were used. The rats were anesthetized with intraperitoneal pentobarbital $35 \mathrm{mg} / \mathrm{kg}$. Doses were prepared as 0.1 $\mathrm{ml} / 100 \mathrm{~g}$ of body weight and used to induce anesthesia. The rat's dorsum was shaved of $4 \mathrm{~cm}$ width. The shaver was held at a $45^{\circ}$ angle to the skin and only two passes across the same area was allowed to minimize skin trauma. The area for burn infliction was $12 \times 8 \mathrm{~cm}$, limited to the loin. The upper boundary was marked out by palpation of the twelfth ribs bilaterally by drawing a horizontal line below them. The lower boundary was marked by palpation of the pelvic bone by drawing horizontal line above it. Palpating for and drawing a vertical line following the course of the vertebral spinouts processes marked out the midline. A horizontal line dividing the upper and lower skin layers was also drawn. These lines divided the loin into four equal areas where burns were imposed, each quadrant accommodating a single burn wound. The skin was disinfected with $70 \%$ isopropyl alcohol. The skin was left to dry and equilibrate to the ambient temperature for 3 minutes.

\section{Ethical approval}

Ethical approval for this research was given by the Bioethics Committee at the Biotechnology Research Center (BEC-BTRC), with Ref. No. (BEC-BTRC 192019).

\section{Creation of burn wounds}

A cylindrical stainless steel rod (100 $\mathrm{g}$ and $1 \mathrm{~cm}$ diameter) was heated to $100^{\circ} \mathrm{C}$ by immersing it in a flask of boiling water before inflicting each burn. Sedation depth was assessed by performing two consecutive toe-pinch tests on two different limbs. Using the thumb and index finger of both hands, a portion of skin was pulled up, directing the two sides upwards and outwards to maintain a flat skin surface. The hot rod was lifted off the flask and placed perpendicular onto the skin. Rod transfer from the boiling water to the skin took 3 seconds to minimize heat lost. The heated rod was held in contact with the skin for 20 seconds in each of the four quadrants. Each quadrant accommodated a single burn wound.

\section{Wound evaluation}

Wound size was measured by a ruler directly after burn infliction. Wound morphology in terms of color and margin was evaluated. The wounds were excised directly after evaluation of morphology and size using scalpel then fixed in formalin for pathologist examination.

\section{Shea application}

One mm thickness of Shea butter was applied on the surface of the burned areas. Damage was scored after 1 hour, 72 hours, and 1 week. Morphology, image, and histopathology were also scored during time of experiment.

\section{Experiment design}

One rat was kept as control at zero time. One group named group one (four rats) after 72 hours: one rat as control, one treated with control sample, one treated with sample from Poland T1, and one treated with random local sample T2. Group two was divided the same way and the results were taken after 1 week.

\section{Microscopic examination}

Paraffin was used for processing and molding; consequently, transverse incision, including skin and wound bed thickness of 5-7 $\mu \mathrm{m}$, was prepared. The prepared slices were colored with hematoxylin and eosin staining method (Bancroft and Gamble, 2002). Samples were estimated using pathological parameters, including inflammatory cells, epithelization, and vascularity.

\section{Results \\ Burn healing activity results on rats \\ Burns on rat skin were evaluated morphologically according to the wound condition and healing and change in color, in addition to microscopical evaluation using pathological parameters, including epithelization, inflammatory cells, and vascularity.}

\section{Burn morphology and size results}

Evaluation according to the morphological level showed that the control sample, bought as raw Shea butter from South Africa, caused a negative effect on the burn healing process. This appeared as pus and discharges from the burn wound, starting from 72 hours and getting worse after 1 week of the experiment time (Fig. 1), while the sample that was chosen randomly 
from the local market (T2) showed better results (Fig. 2). At the same time, the sample from Poland (T1) was the best among the tested samples, whereas the burn wound was in good condition after 1 week in addition to a clear growth of hair in the shaved areas that were treated with T1 (Fig. 3).

\section{Microscopy results (histopathology)}

Processing and molding using paraffin and incision, including skin and wound bed, resulted in slices which were colored to be evaluated depending on pathological parameters, such as epithelization, inflammatory cells, and vascularity. At the end of the experiment, the burn wounds of this study ranged from superficial second degree to deep second degree. There are different histological pictures of the burned control, 72 hours burned skin, and 1 week burned skin. Specimens were taken from the burnt skin of control, burn animals, as well as from normal treated ones.
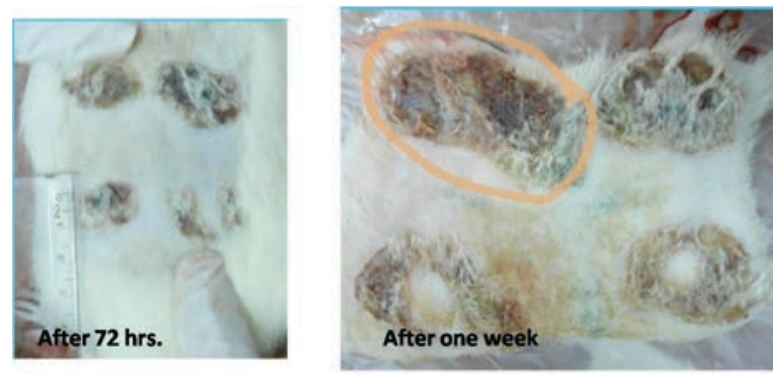

Fig. 1. Burn healing result of Shea butter control sample after (A) 72 hours and (B) 1 week of treatment.

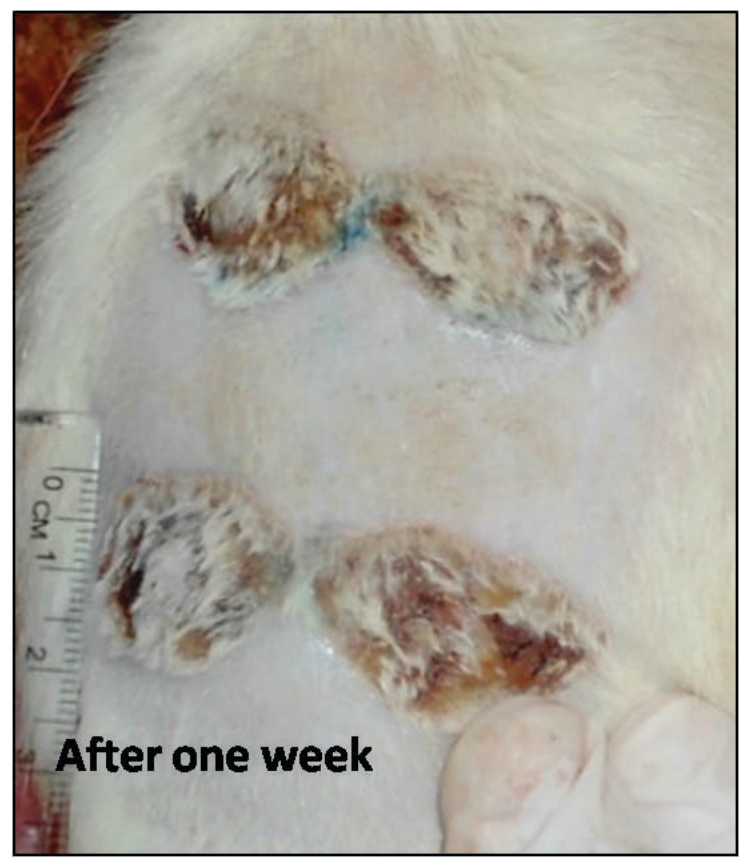

Fig. 2. Burn healing result of Shea butter sample (T2) after 1 week of treatment.

\section{Microscopic result of normal skin}

In the control group, after using the H\&E stain, the skin formed the epidermis and dermis. The epidermis consists of stratified squamous epithelium with keratin, and the dermis was clearly divided into papillary layers; underneath the epithelium contained dermal papillae, blood vessels, and loose connective tissue (with fine collagen fibers and a reticular layer). The reticular layer consists of dense collagenous connective tissue containing sweat glands and their ducts, well-developed hair follicles, and prominent sebaceous glands (Fig. 4a).

\section{Microscopic result of burned untreated skin}

In the burned untreated section obtained on day 1 of the study, the epidermis and a variable depth in the dermis were clearly affected. The tissue was sloughed off and replaced by necrotic tissue; however, the deep dermal structures were viable. Thrombi blocked the blood vessels, in addition to infiltration of a large number of inflammatory cells forming a zone demarcating, the junction between necrotic and viable tissue (Fig. 4b).

After 72 hours, the induced burn skin section, which was stained by H\&E stain, showed a clear degeneration of the skin architecture; there was a complete degeneration in the epidermis as well as the rest of the epidermal cells which became necrotic forming a dead layer on the burn. The hair roots disappeared from some burned skin regions and degenerated in other regions. At the base of the burnt area, there were significant mononuclear phagocytic cells (MNP cells) infiltrations in the dermis. This layer was formed by collagen fibers and dominated fibroblasts cells between the collagen fibers (Fig. 5a).

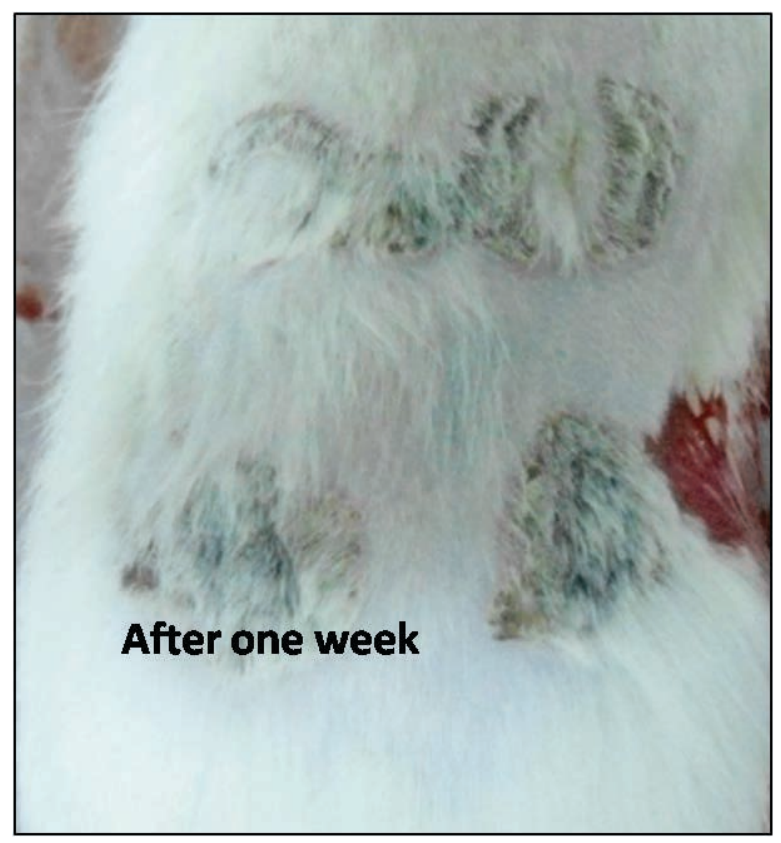

Fig. 3. Burn healing result of Shea butter sample from Poland (T1) after 1 week of treatment. 

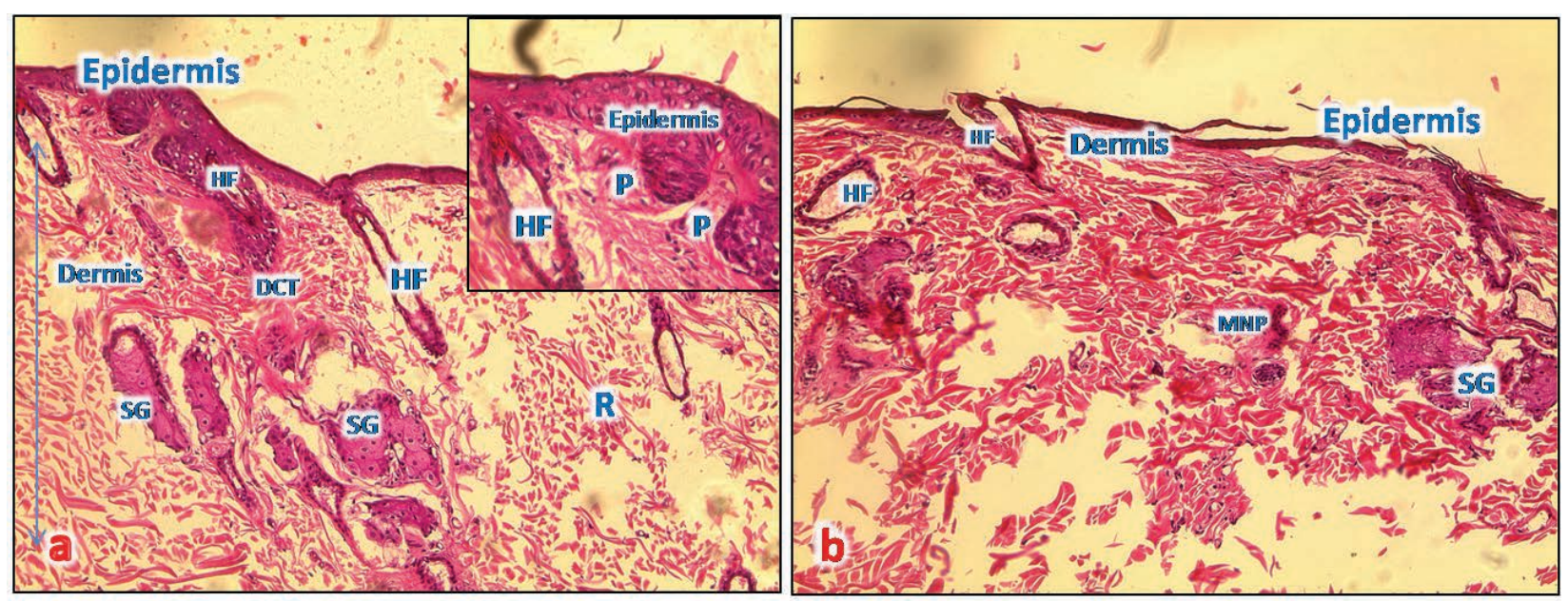

Fig. 4. (a): A photomicrograph of the section of thin skin tissue from the control group showing the epidermis layer and dermis differentiated into papillary (P) and reticular (R) layers. Note the hair follicles (HF), sebaceous glands (SG), and well-defined dense collagenous tissue (DCT) (H\&E, 10x). (b) A photomicrograph of H\&E section of thin skin tissue from burnt skin obtained on day 1 of the study group showing the necrotic epidermis and the affected dermis infiltrated by mononuclear phagocytic cells (MNP) (H\&E, 10x).
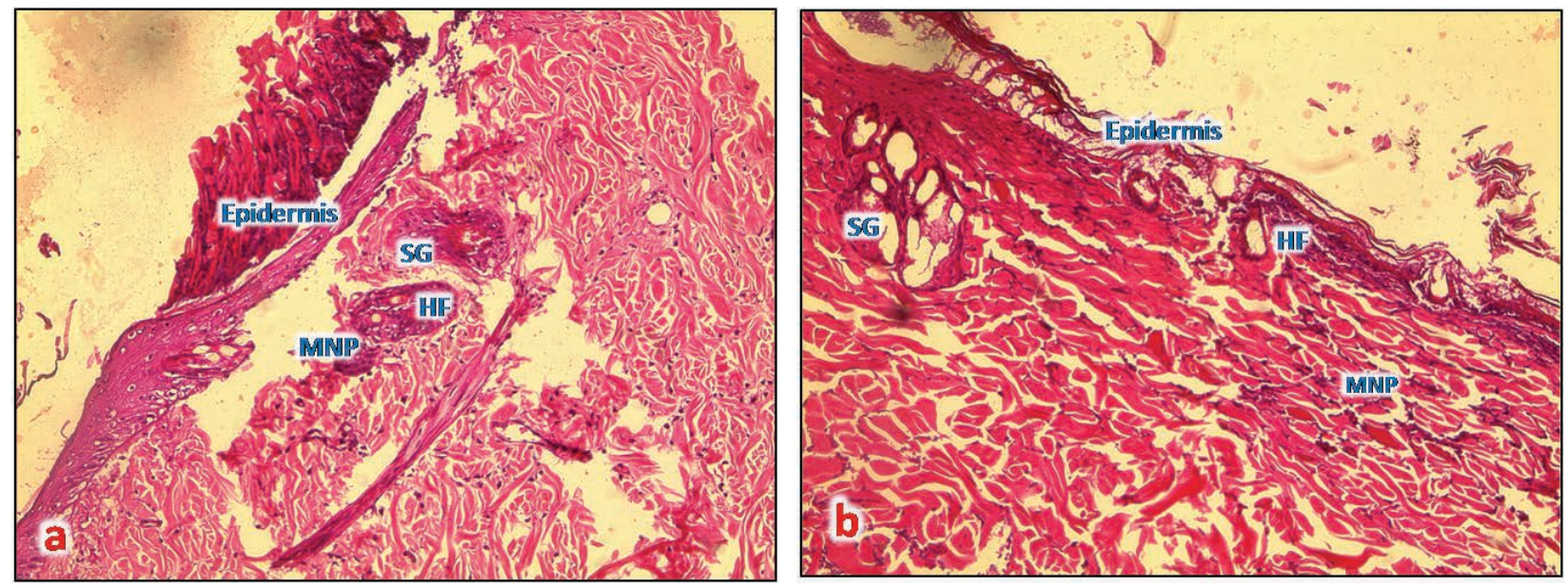

Fig. 5. (a) A photomicrograph of the section of thin skin tissue from skin tissue obtained on 72 hours after burning showing the inflammatory cells infiltration (MNP) around newly formed rest of hair follicles and sebaceous glands (SG) (H\&E, 10x). (b) A photomicrograph of the section of burnt skin tissue obtained 1 week after burning showing the inflammatory cells infiltration (MNP), loss of epidermis, sebaceous glands (SG), and hair follicle (HF) (H\&E, 10x).

After 1 week from the burn infliction, in the H\&E stained skin sections, massive damages of the epidermis, where there was no more epithelium and lysis of keratin layer, complete damage of hair follicle and sweat glands and significant collagen deposition rather than inflammatory cells was seen (Fig. 5b).

Microscopic result of normal skin treated with samples of Shea butter

The skin sections around burned skin treated with control sample from South Africa, show restored epidermal and dermal layer, and a horny layer, and the epidermal cells appeared thicker compared to control ones with normal appearance of and normal blood vascularization (Fig. 6a and b).

\begin{abstract}
Microscopic result of burned skin treated with samples of Shea butter (T1)

In sections of skin burn treated with $\mathrm{T} 1$ for 72 hours, there were less inflammatory cells infiltrate at the base of the burnt area, the epidermis had slight erosions, necrosis of hair follicles and sebaceous glands, and congested blood vessels (Fig. 7a).

In sections of skin burn treated with T1 for 1 week, there were massive inflammatory cells around the damaged hair follicles and infiltrates at the base of the burnt area, forming granular tissues. The epidermis was lost, necrosis of sebaceous glands, and congested area around the follicles (Fig. 7b).
\end{abstract}



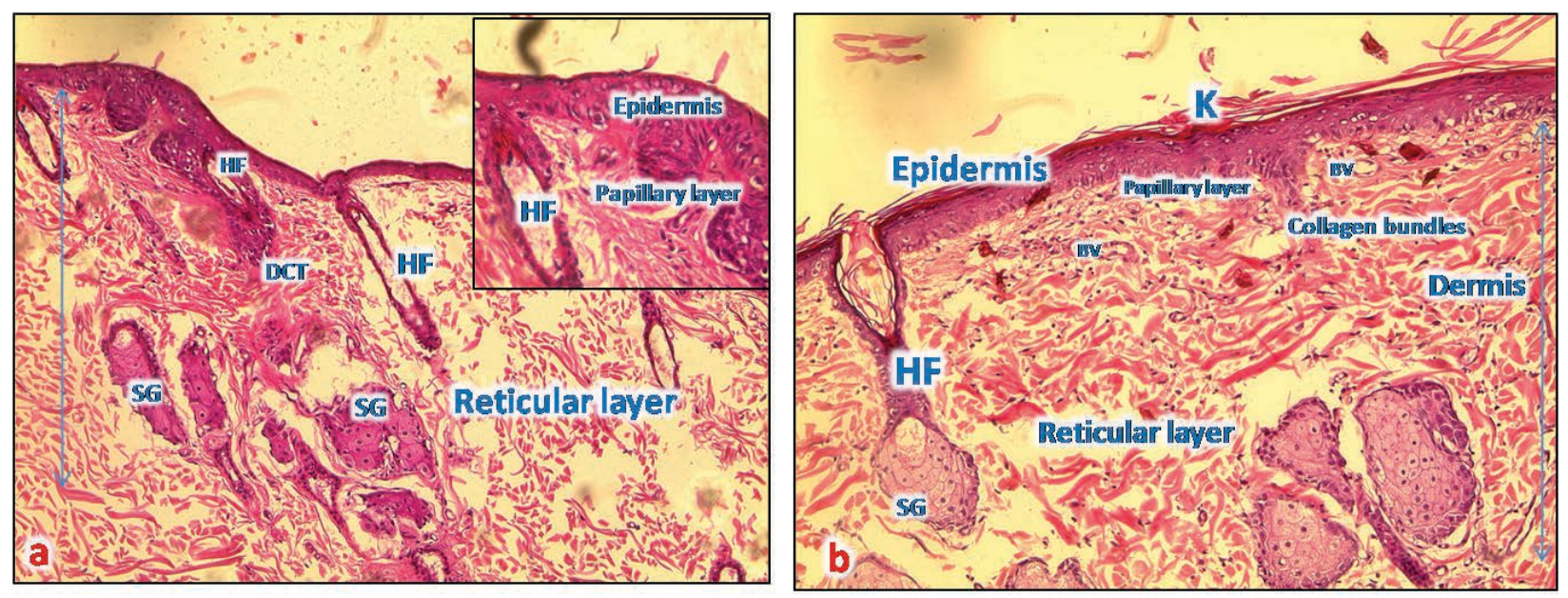

Fig. 6. (a) A photomicrograph of the section of thin skin tissue from unburned regions showing the (a) section of thin skin tissue from control group showing the epidermis layer and dermis differentiated into papillary (P) and reticular (R) layers. Note the hair follicles (HF), sebaceous glands (SG), and well-defined dense collagenous tissue (DCT) (H\&E, 10x). (b) Section from normal skin treated with control sample showing restored epidermal and dermal layers, and a thorny keratinized layer (K); the epidermal cells appear thicker than that of control ones with a normal appearance of all dermal appendages (HF and SG) with normal blood vessels (BV).
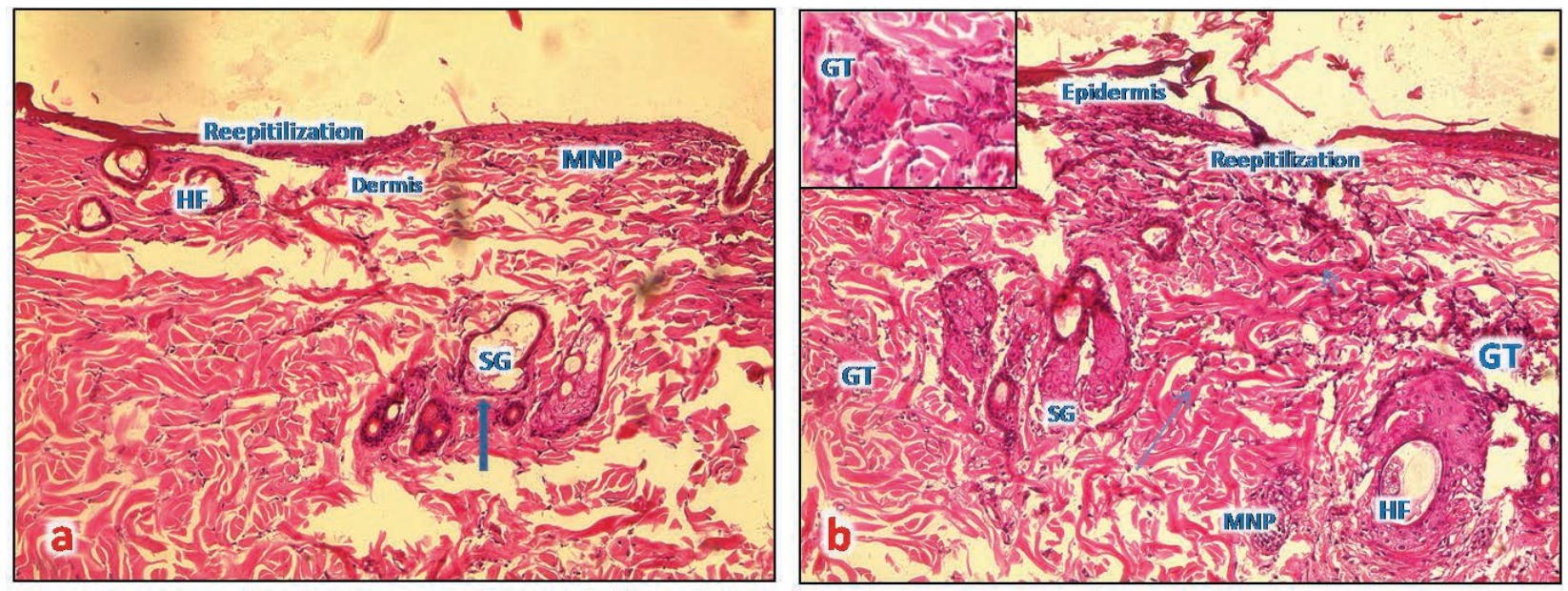

Fig. 7. (a) A photomicrograph of the section of $\mathrm{T} 1$ treated group for 72 hours showing the reepithelization at the edge of burned tissue, destroyed hair follicles (HF), and infiltration of MNP cells (H\&E, 10x). (b) A photomicrograph of section of T1 treated group for 1 week showing proliferative granulation tissue (GT) with accumulation of fibroblasts (arrows) and inflammatory cells (MPC) around hair follicles (HF), sebaceous glands (SG), and sweat gland duct in the dermis (H\&E, 10x).

\begin{abstract}
Microscopic result of burned skin treated with samples of Shea butter (T2)

In sections of skin burn treated with $\mathrm{T} 2$ for 72 hours, slight improvement of the epithelium of epidermal layer with loss of keratin and inflammatory cells were observed in large numbers to immigrate below the keratin of burned epidermis and around necrotic sebaceous glands and hair follicle, deep dermis layer showed normal collagen bundles, but with necrotic sweat gland (Fig. 8a).

In sections of skin burn treated with T2 for 1 week, complete loss of epidermis and degenerated hair follicles and sebaceous glands were present, but with massive accumulation of granular tissue underneath the epidermal layer (Fig. 8b).
\end{abstract}

\section{Microscopic result of burned skin treated with samples of Shea butter (ST)}

In sections of skin burn treated with ST for 72 hours, complete loss of epithelium and massive infiltration with MNP cells (Fig. 9a) were seen. In sections of skin burn treated with ST for 1 week, the inflammatory cells infiltrate had decreased significantly compared with burn group, the epidermal layer, hair follicle and sebaceous glands appear normal, and the dermal region containing well-defined collagen fiber (Fig. 9b).

Figure 10 shows the list of ingredients added to Shea butter product (T1) from Poland. 

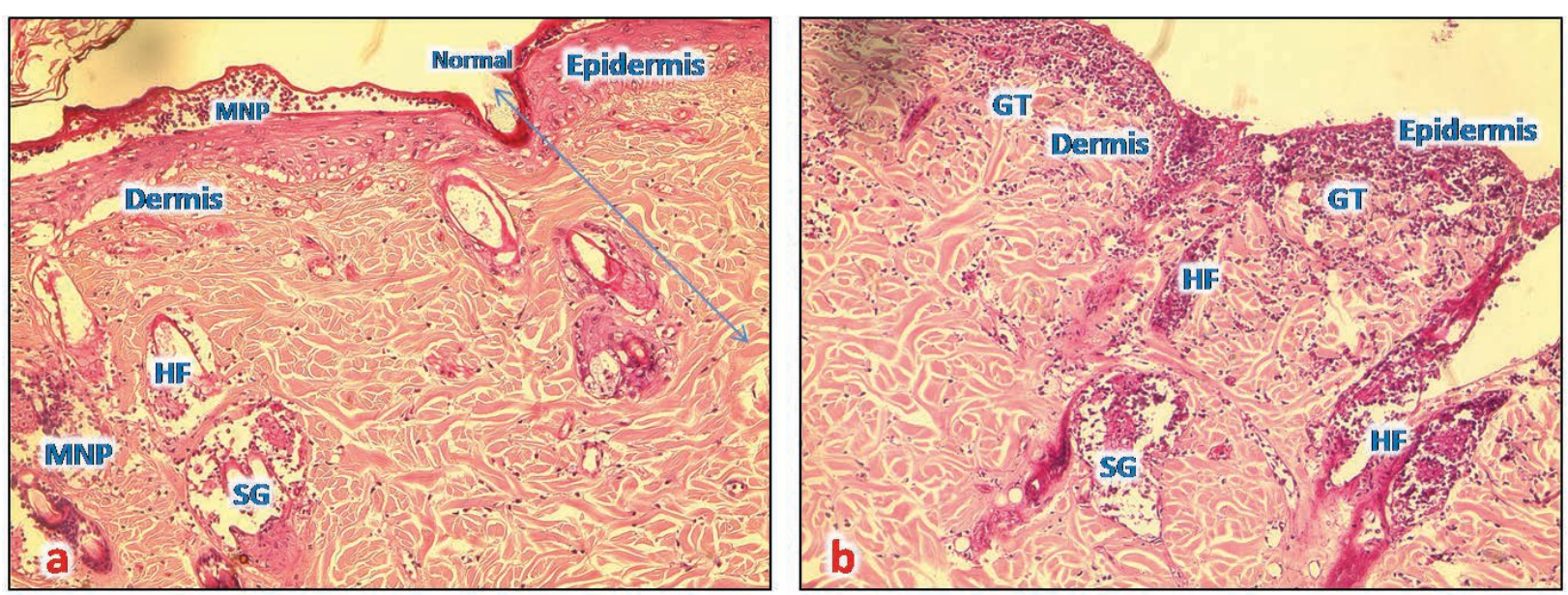

Fig. 8. (a) A photomicrograph of section treated with $\mathrm{T} 2$ for 72 hours showing the upper right show normal skin layer at the edge of this section, accumulation of MNP cells at epidermis of affected area, around affected hair follicles (HF), and sebaceous glands (SG) (H\&E, 10x). (b) A photomicrograph of skin tissue treated with T2 for 1 week showing massive granular tissue (GT) at the rest of epidermis and at dermal region (H\&E, 10x).
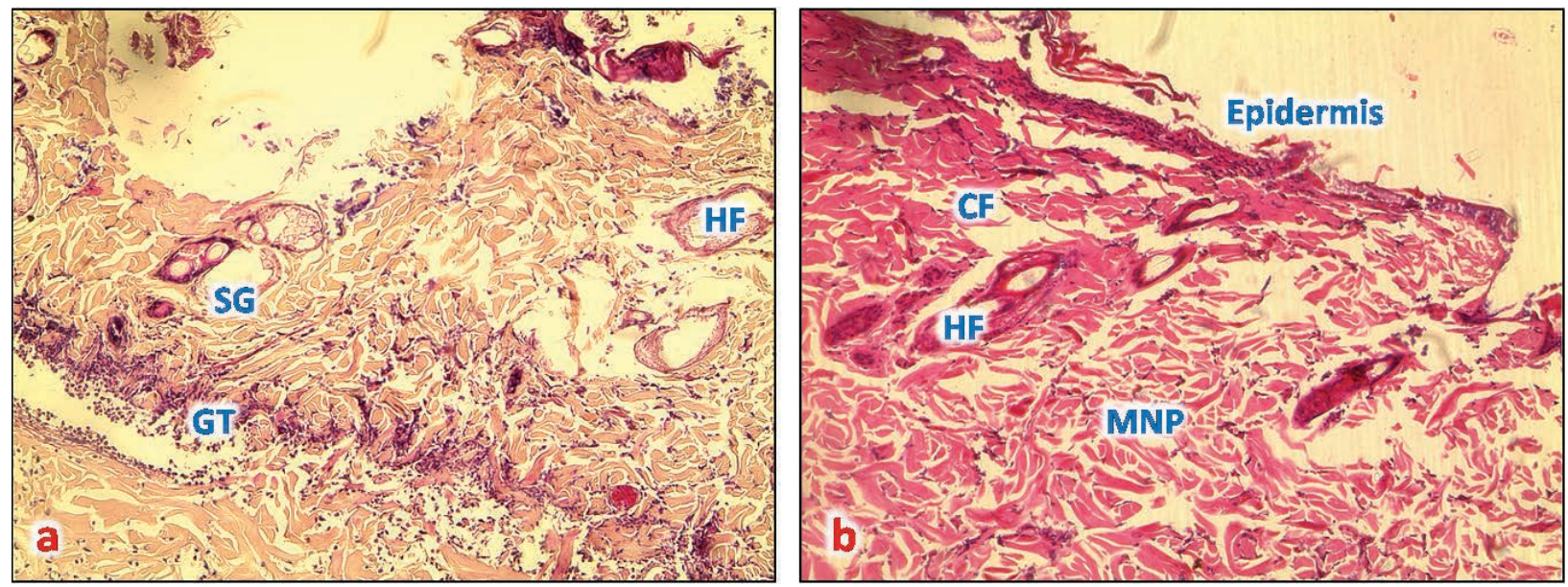

Fig. 9. (a) A photomicrograph of the skin tissue treated with ST for 72 hours showing the destroyed epidermal layer (upper right), hair follicles (HF), and sebaceous glands (SG) accumulation of MNP cells (GT) (H\&E, 10x). (b) A photomicrograph of the skin tissue treated with ST for 1 week showing the upper slight reepithelization at the edge of the affected area, (MNP) around affected hair follicles (HF), sebaceous glands (SG), and well-defined collagen fiber (CF) (H\&E, 10x).

\section{Discussion}

In order to evaluate Shea butter's role in the treatment of skin burn wounds, we treated the burned area of skin by application of thin film of Shea butter. Damage was scored after 1 hour, 72 hours, and 1 week. The results of burn morphology and size showed that the control sample bought as raw Shea butter from South Africa caused a negative effect on burn healing process. It appeared with pus and discharge on the burn wound starting from 72 hours and getting worse after 1 week of the experiment, while the sample that was chosen randomly from the local market (T2) showed better results. At the same time, the sample from Poland (T1) was the best among the tested samples, and the burn wound was in good condition after 1 week in addition to a clear growth of hair in the shaved areas that were treated with $\mathrm{T} 1$; this result can be explained as the Shea butter raw sample (control) bought from South Africa without any treatment, sterilization, or processing because of this it might contain microorganism that is new in our environment which causes infection and inflammation. At the same time, the sample from Poland (T1) improved healing process because of the list of ingredients as anti-inflammatory compounds. There was enhancement of immune response in the form of the presence of large number of inflammatory cells in burn wounds dermis. This opinion was supported by Akihisa et al. (2010) who suggested that shea nuts and Shea fat (Shea butter) compose a significant source of 


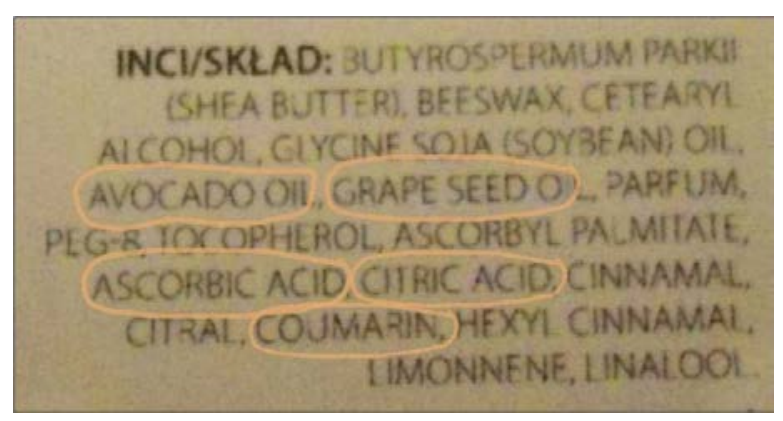

Fig. 10. List of ingredients added to the Shea butter product from Poland.

anti-inflammatory and anti-tumor promoting compounds called cinnamate esters. A study of lipopolysaccharideactivated macrophage cells, Shea butter showed antiinflammatory effects by iNOS, COX-2 inhibition, and cytokines via the NF-KB pathway. Histologically, in the normal skin treated with samples of Shea butter in our study, well-developed sebaceous glands and hair follicles were prominent in all sections (Nandini et al., 2012). Additional research has shown that the Shea butter melts at body temperature, acts as a "refattening" agent, has good water-binding properties, and rapidly absorbed into the skin; making it useful for skin care (Hemat, 2003). Renard (1990) reported that raw Shea butter can encourage regeneration of cell tissue and skin softening, which decrease the appearance of fine lines and wrinkles and diminished various aging signs.

The ingredients added to Shea butter product (T1) from Poland according to our finding are the good effect of T1 sample, and this might be because of the added compounds, such as avocado oil, grape seed oil, citric acid, ascorbic acid, coumarins, and others. Hon et al. (2015) have shown that the skin products containing Shea butter extract had the same efficacy as ceramide-precursor product.

Additional research (Maranz et al., 2004) reported that Shea butter consist of triglycerides with oleic, stearic, linoleic, and palmitic fatty acids, in addition to unsaponifiable compounds.

\section{Conclusion}

The histological study indicates that Shea butter bought as raw might have a bad effect on burned skin. On the other hand, the treatment of burned skin with T2 for 72 hours showed slightly significant healing to the normal structure, whereas the 1-week treated group showed proliferative granulation tissue with fibroblasts accumulation and inflammatory cells in the dermis and neighboring sebaceous glands and hair follicles, small areas of epidermis formed of few layers were observed and some hair roots were also grown; this is well seen in case of T1 and T2, while the sample from Poland had a therapeutic effect and this might be because of the additives, such as avocado oil, grape seed oil, citric acid, ascorbic acid, coumarins, and others. However, further research studies are needed to confirm the beneficial usage of Shea butter in the treatment of burn wounds.

\section{Conflict of interest}

The authors declared no conflicts of interest in addition to the lack of financial support for funding of this study.

\section{References}

Akihisa, T., Kojima, N., Kikuchi, T., Yasukawa, K., Tokuda, H.T., Masters, E., Manosroi, A. and Manosroi, J. 2010. Anti-inflammatory and chemopreventive effects of triterpene cinnamates and acetates from shea fat. J. Oleo. Sci. 59(6), 273280.

Bancroft, J.D. and Gamble, M. 2002. Theory and practice of histological techniques, 5th ed. Philadelphia, PA: Churchill Livingstone, pp: 125138.

Demling, R.H. and Seigne, P. 2000. Metabolic management of patients with severe burns. World J. Surg. 24, 673-680.

DeSanti, B. S. 2005. Pathophysiology and current management of burn injury. Adv. Skin Wound Care. 18(6), 333-334.

Hall, J.B., Aebischer, P.D., Tomlinson, H.F., Osei-Amaning, E. and Hindle, J.R. 1996. Vitellariaparadoxa: a monograph. School of Agricultural and Forest Sciences. Bangor, UK: University of Wales, pp: 105.

Hemat, R.A.S. 2003. Principles of orthomolecularism. Urotext, pp: 160.

Hon, K.L., Tsang, Y.C., Pong, N.H., Lee, V.W., Luk, N.M., Chow, C.M. and Leung, T.F. 2015. Patient acceptability, efficacy, and skin biophysiology of a cream and cleanser containing lipid complex with shea butter extract versus a ceramide product for eczema. Hong Kong Med. J. 21, 417-425.

Hong, T.D., Linington, S. and Ellis, R.H. 1996. Seed storage behaviour, acompendium. Rome, Italy: Handbook for Genebanks: No. 4 Intl Plant Genetic Resources Inst.

Maranz, S., Kpikpi, W., Wiesman, Z., Saint Sauveur, A. and Chapagain, B. 2004. Nutritional values and indigenous preferences for shea fruits (Vitellariaparadoxa) in African agroforestry parklands. Econ Bot. 58, 588-600.

Monafo, W. and Bessy, P. 2001. Wound care in total burn care. In: bcE,Herndon, D. Philadelphia, PA: WB Saunders, pp: 109.

Nandini, V., Rina, C., Rakha, H.D. and Hemant, K.G. 2012. Anti-inflammatory effects of shea butter through inhibition of iNOS, COX-2, and cytokines via the Nf-Î'B pathway in LPS-activated J774 macrophage cells. J. Complement Integr. Med. doi: 10.1515/1553-3840.1574.

Renard, R. 1990. Le buerrede karate. ThÃ@se de Doctorat en Pharmacie. UFR de sciences pharnacuetiques. Universite de Bordeaux II, pp: 100.

Williams, W. 2001. Pathophysiology of the burn wound. In: Herndon, D., ed. Total Burn Care. Philadelphia, PA: WB Saunders, pp: 514. 